\title{
Characterization of Interference Thin Films Grown on Stainless Steel Surface by Alternate Pulse Current in a Sulphochromic Solution
}

\author{
Rosa Maria Rabelo Junqueira ${ }^{\mathrm{a} *}$, Célia Regina de Oliveira Loureiro ${ }^{\mathrm{a}}$, \\ Margareth Spangler Andrade ${ }^{\mathrm{a}}$ Vicente Tadeu Lopes Buono ${ }^{\mathrm{b}}$ \\ a Setor de Tecnologia Metalúrgica, \\ Fundação Centro Tecnológico de Minas Gerais - CETEC, \\ Av. José Cândido da Silveira, 2000, 31170-000 Belo Horizonte - MG, Brazil \\ ${ }^{\mathrm{b}}$ Departamento de Engenharia Metalúrgica e de Materiais, \\ Universidade Federal de Minas Gerais - UFMG, \\ Rua Espirito Santo 35, 30160-030 Belo Horizonte - MG, Brazil
}

Received: April 2, 2008; Revised: October 28, 2008

\begin{abstract}
The aim of this work was to characterize thin interference films grown on the surface of AISI 304 stainless steel for decorative purposes. Films were grown in a sulphochromic solution at room temperature by an alternating pulse current method. The morphology and chemical state of the elements in the films were investigated by field emission scanning electron microscopy (FESEM), atomic force microscopy (AFM), glow discharge optical emission spectrometry (GDOES), and infrared Fourier transform spectroscopy (FTIR). Depth-sensing indentation (DSI) experiments and wear abrasion tests were employed to assess the mechanical resistance of the films. The coloration process resulted in porous thin films which increased the surface roughness of the substrate. The interference films mainly consisted of hydrated chromium oxide containing iron. Increasing film thickness produced different colors and affected the mechanical properties of the coating-substrate system. Thicker films, such as those producing gold and green colors, were softer but more abrasion resistant.
\end{abstract}

Keywords: interference films, colored stainless steel, AFM, wear abrasion resistance

\section{Introduction}

Deposition of thin interference films on the surface of stainless steel is an important method to enhance the decorative and architectural application of these materials. A wide range of interference colors, including brown, blue, gold, purple, and green can be obtained as the film thickness increases from tenths of nanometres to about a half micrometer ${ }^{1}$. In addition, the thin layer of oxide film grown on stainless steel generally improves surface properties ${ }^{2}$, thus increasing its potential applications. The first process known to be applied to produce the interference coloring of stainless steel is the INCO process, in which the steel is chemically treated in a hot solution of sulphuric acid containing chromate ions ${ }^{3,4}$. Electrochemical methods using square wave potential pulse polarization in hot sulphuric acid solutions were later developed ${ }^{5}$. A similar method, with the advantage of using sulphochromic solutions at room temperature, was also applied to grow these interference oxide films on the surface of stainless steel ${ }^{6,7}$.

The successful performance and reliability of these interference films are generally limited by their resistance to the scrubbing action of routine cleaning operations. However, testing of architectural coatings is often a measure of a complex interaction of various physical characteristics of the coating. The characterization of film structure, composition, and morphology is the first step towards understanding the reactions taking place during deposition so as to control film properties and to develop new products and processes. It has been demonstrated that the mechanical resistance of interference films is affected by the deposition process ${ }^{8}$. By using depth-sensing methods, it was found that the morphology of electrochemically deposited interference films plays an important role in determining their mechanical resistance ${ }^{9}$.

Considering that this kind of film is made up of very small structures, high resolution techniques, such as atomic force microscopy (AFM) and field emission scanning electron microscopy (FESEM), are needed to analyze their morphology. Therefore, such studies are scarcely found in the literature. The thickness and in-depth composition of these films have been investigated using Auger electron spectroscopy (AES) and secondary ion mass spectrometry (SIMS) $)^{10,11}$. These studies showed that electrochemically deposited interference films on stainless steel surfaces are mainly constituted of chromium oxide. Other studies using X ray photoelectron spectroscopy (XPS) have confirmed the presence of chromium in the form of $\mathrm{Cr}(\mathrm{III})$ and have indicated the presence of $\mathrm{Fe}$ and $\mathrm{Ni}$ within the interference film ${ }^{12,13}$.

The present study intends to contribute to the understanding of the nature of interference films grown by alternating pulse current on austenitic stainless steel. The morphology and the chemical state of the elements in the films were investigated by FESEM, AFM, GDOES (glow discharge optical emission spectrometry) and FTIR (infrared Fourier transform spectroscopy). Depth-sensing indentation (DSI) experiments and wear abrasion tests were employed to assess the mechanical resistance of the films. 


\section{Experimental}

\subsection{Sample preparation}

Specimens of $200 \times 200 \times 0.8 \mathrm{~mm}$ were cut from a sheet of bright buffing (BB) type AISI 304 stainless steel, degreased in ethanol, and rinsed in distilled water before immersion in an aqueous solution containing $2.5 \mathrm{M} \mathrm{CrO}_{3}$ and $5.0 \mathrm{M} \mathrm{H}_{2} \mathrm{SO}_{4}$, for coloration by means of the alternating pulse current method, at room temperature, as previously described elsewhere ${ }^{9}$. The color tones of the samples were controlled by the chroma coordinates: L (brightness), C (chroma), and $\mathrm{h}$ (hue), characteristic of brown, blue, gold, and green colors. These coordinates were measured in a reflectance spectrophotometer using a $\mathrm{D}_{65}$ light source and a $10^{\circ}$ standard observer. The measurement of reflectance was conducted in a ColorQuest II - HunterLab reflectance spectrophotometer, for wavelengths in the range of 400 to $700 \mathrm{~nm}$.

\subsection{Morphological analysis}

FESEM images were acquired in a Hitachi ${ }^{\circledR}$ S5000 at $2.0 \mathrm{kV}$ and 100,000 to 300,000 magnifications for each sample in order to characterize the morphology of the interference films. The film roughness was evaluated from AFM images acquired in a Digital Dimension 3000 equipment, operating in intermittent contact mode using a silicon nitride tip. The scan size was $2 \times 2 \mu \mathrm{m}$. The roughness, expressed as the root mean square $\left(\mathrm{R}_{\mathrm{q}}\right)$ parameter, was obtained after having processed nine AFM images for each sample.

\subsection{GDOES analysis}

The depth-concentration profiles of the coatings were obtained by GDOES analysis using a Shimadzu GDLS 9950 RF instrument. Specimens colored in brown, blue, gold, and green were sputtered in a high purity $(99.999 \%)$ argon atmosphere of $25 \mathrm{~Pa}$ by applying a radio frequency of $13.56 \mathrm{MHz}$ at a power of $20 \mathrm{~W}$. The inner diameter of the anode was $4 \mathrm{~mm}$. Three samples of each of the four colors were employed and three measurements were performed in one sample, totaling nine measurements for each color. The tests were conducted in sequence on the same day to avoid the oscillations inherent to the technique.

\subsection{FTIR analysis}

The chemical bonding of the films were characterized by FTIR reflection spectra in the spectral range from 4,000 to $500 \mathrm{~cm}^{-1}$, obtained in the stainless steel substrate and in gold colored samples using a Nicolet Nexus 470 spectrometer.

\subsection{Depth-sensing indentation experiments}

DSI experiments were performed in a Shimadzu DUHW201S instrumented indentation tester with a load range of 0.1 to $1960 \mathrm{mN}$, a maximum penetration depth of $10 \mu \mathrm{m}$ and an indenter shift resolution of $1 \mathrm{~nm}$. A Berkovich triangular pyramid with $115^{\circ}$ tip angle was used as an indenter. A load of $5 \mathrm{mN}$ was applied at a rate of $0.178 \mathrm{mN} / \mathrm{s}$. The holding time was 5 seconds, and load-displacement curves were registered in all experiments.

The DSI measurements were carried out on the stainless steel substrate as well as on specimens colored in brown, blue, gold, and green. A minimum of five experiments were performed per load. From the load-displacement data, the values of elastic modulus and hardness of the interference films were calculated using the Oliver \& Pharr approach ${ }^{14}$.

\subsection{Wear abrasion resistance}

Dry abrasion resistance experiments were performed on a SUGA NUS-ISO3 abrasion tester machine for coated materials. The specimens were submitted to a sliding movement back and forth on a horizontal plane under a load of $30 \mathrm{~N}$, and their surface was abraded by reciprocal motion against a strip of a $0.5 \mu \mathrm{m} \mathrm{CrO}_{3}$ abrasive paper attached do the outer circumference of a turning wheel. Nine experiments were performed for each color, and the mean number of strokes necessary to expose the substrate was recorded as the wear abrasion resistance of the coating.

\subsection{Statistical analysis}

Analysis of variance for completely randomized design ${ }^{15}$ and Duncan post hoc test at an alpha level of $0.05^{16}$ were adopted to compare the results of roughness and thickness measurements as well as the mechanical properties of the different coatings.

\section{Results and Discussion}

\subsection{Morphology}

The surface morphology of the interference film is illustrated in Figure 1 by means of a typical FESEM image for a gold colored sample, in which pores and discontinuities can be observed. The topography of the film is shown in the AFM images of the same sample and of the steel substrate presented in Figure 2. The tridimensional images show the smoother surface of the substrate when compared to the surface of the film. This evidence was reinforced by the mean roughness $\left(R_{q}\right)$ values of $3.6 \pm 0.7 \mathrm{~nm}$ and $4.9 \pm 0.8 \mathrm{~nm}$ obtained for the uncovered substrate and the colored sample, respectively. A significant difference was found between these values, indicating that the film has a higher roughness than the substrate.

\subsection{Film thickness}

Typical GDOES depth profiles for $\mathrm{Fe}, \mathrm{O}, \mathrm{Cr}$, and $\mathrm{Ni}$ in the brown, blue, gold, and green samples are shown in Figure 3. For all four colors, a sharp decrease in oxygen and an increase in iron were observed until a steady and constant intensity was reached, thus allowing for the location of a metal/film interface at the intersection point of the oxygen and iron lines. As established by Kerber \&

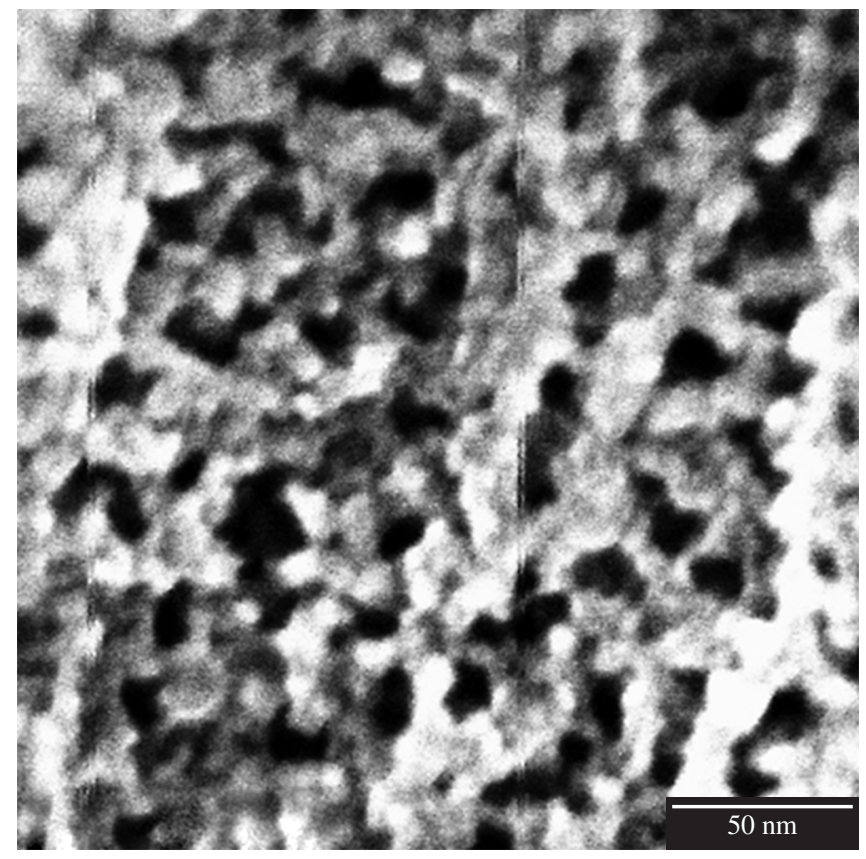

Figure 1. Typical FESEM image of a gold colored interference film. 


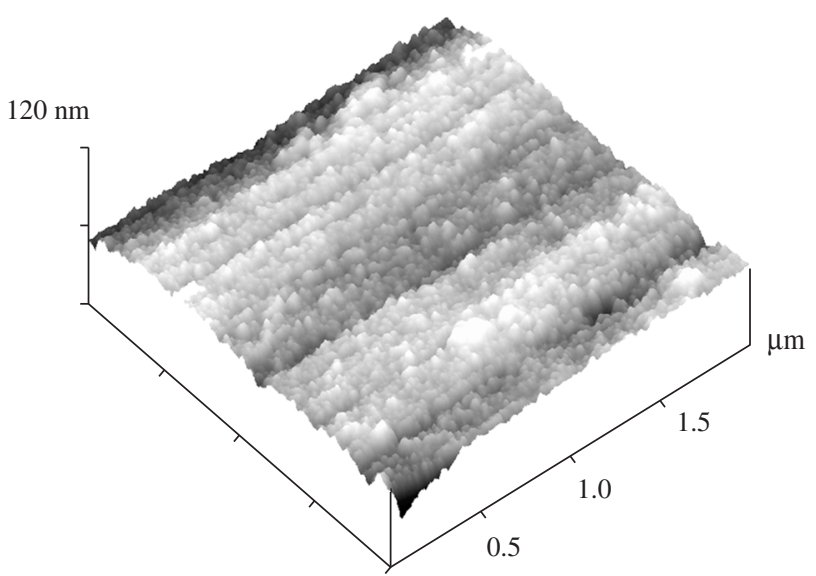

(a)

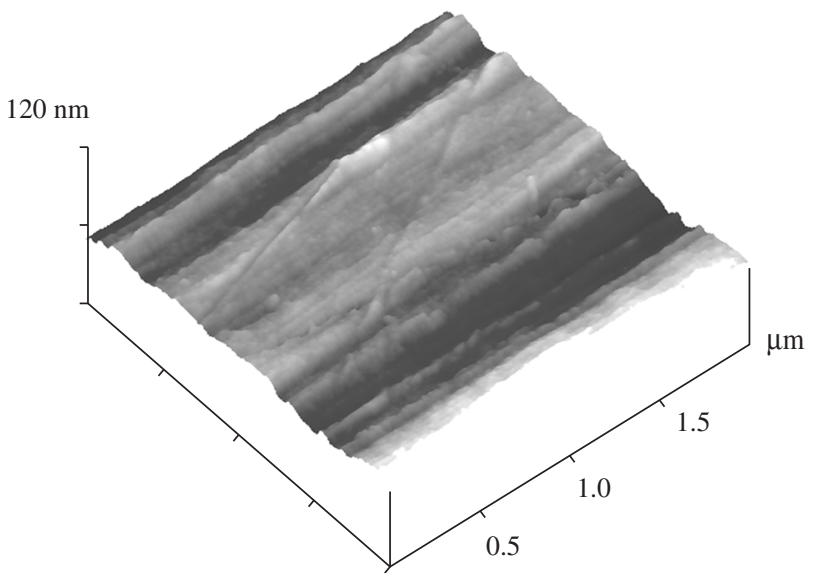

(b)

Figure 2. AFM images of a) a gold colored sample and b) the uncovered substrate.
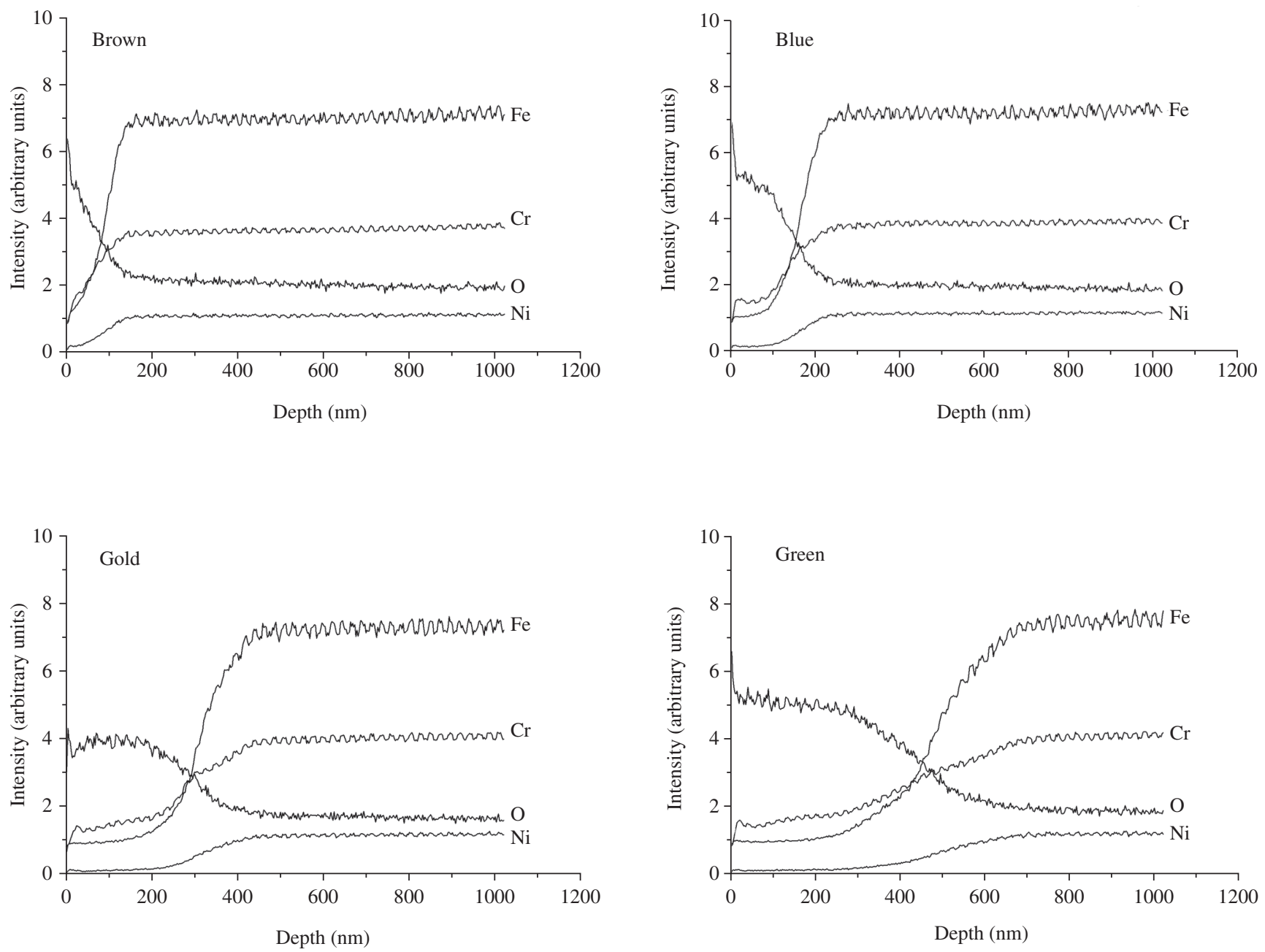

Figure 3. GDOES depth profiles of interference films colored in a) brown, b) blue, c) gold and d) green.

Tverberg ${ }^{17}$ for thickness measurements of passive layers on stainless steel surfaces, film thickness was recorded as the distance from the origin to the intersection of the iron and oxygen traces in the depth profile graph.
An increase in chromium intensity from the film to the substrate can be observed in the depth profile curves. This behavior is not in agreement with the idea that the interference film is homogeneous and formed mainly by chromium oxide. However, this anomalous 
behavior can be attributed to some degree of power loss resulting from the lower emittance of the interference film. Investigating the effect of discharge parameters on emission yields in a radio-frequency glowdischarge emission source. Parker et al. ${ }^{18}$ found that power losses can take place in nonconductive samples, leading to a decrease in the sputtering rates and atomic emission signals of these samples. A similar behavior for iron and oxygen in AES was reported by Lin \& Duh $^{19}$ in a study of interference films deposited by the pulse current method on AISI 304 stainless steel samples. These authors found that the concentration of $\mathrm{Fe}$ in the interference films was lower than that in the substrate.

The mean values of film thickness estimated from GDOES depth profiles are shown in Figure 4. A significant increase in film thickness from $\sim 70 \mathrm{~nm}$ (brown) to $\sim 440 \mathrm{~nm}$ (green) was found in the samples. Similar results were obtained by Evans ${ }^{1}$ for interference films grown on stainless steel by a chemical process. Using reflectance spectrophotometry, Evans ${ }^{1}$ estimated a $400 \mathrm{~nm}$ thickness for the interference film of the green sample. Lin \& Duh ${ }^{19}$ calculated the thickness of interference films grown by pulsed current and chemical methods through the depth profiling of these films using SIMS and found values similar to those shown in Figure 4. They also reported that there was no significant difference in thickness between films made by the pulsed current method and those made by the INCO chemical method.

\subsection{Chemical bonding}

FTIR spectra of the steel substrate and of a gold colored sample are presented in Figure 5. In contrast with the steel substrate, for the colored sample there is a large absorption band centered at $3382 \mathrm{~cm}^{-1}$ corresponding to $\mathrm{O}-\mathrm{H}$ bonding, which can be attributed to water of hydration incorporated within the surface oxide layer. The sharper band at $561 \mathrm{~cm}^{-1}$ is due to a $\mathrm{Cr}-\mathrm{O}$ stretching mode arising from the chromium oxide coating ${ }^{20}$, whereas the less intense band centered at $1136 \mathrm{~cm}^{-1}$ is similar to $\mathrm{Fe}-\mathrm{O}-\mathrm{H}$ bending vibrations in goethite ${ }^{21}$. Smaller-intensity bands were not sufficiently resolved to be helpful in this analysis and can be assigned to contamination from the environment. In the infra-red analysis of interference colored stainless steel carried out by Evans et al. ${ }^{3}$ a strong absorption band on $3370 \mathrm{~cm}^{-1}$, which was attributed to coordination water, and another band in the metal-oxide region revealing the presence of chromium oxide were

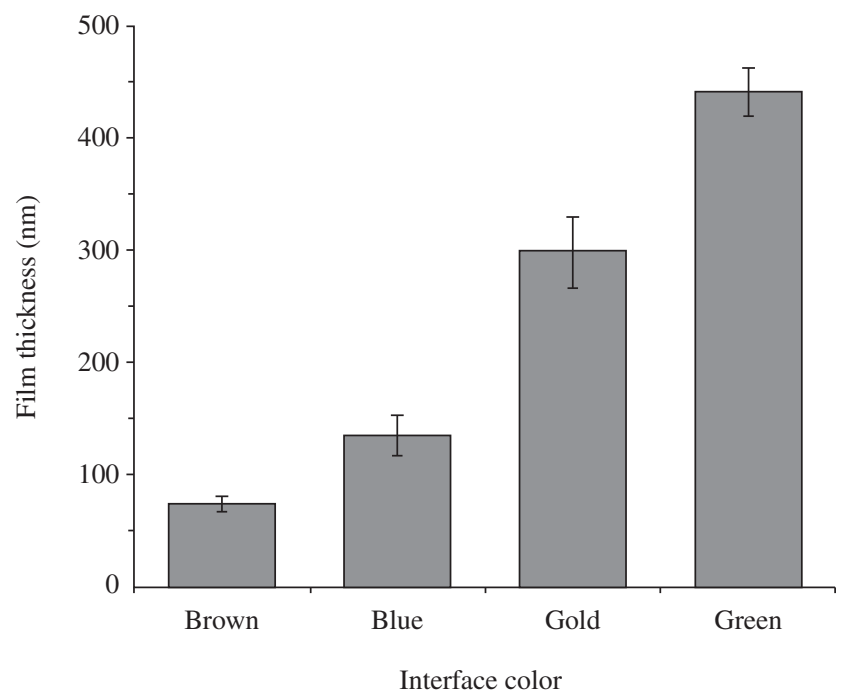

Figure 4. Thickness of interference colored films measured by GDOES technique. detected. In a similar work using TEM/EDS and XPS, Fujimoto et al. ${ }^{12}$ found that the interference film consisted of $\mathrm{a}_{2} \mathrm{FeO}_{4}$ spinel oxide with excess Cr. Thus, the FTIR spectra obtained in the present work indicated that the interference films grown on stainless steel surfaces by means of the electrochemical method are mainly composed of hydrated chromium oxide containing iron.

\subsection{Mechanical properties}

Typical load-displacement curves obtained with a $5 \mathrm{mN}$ load are shown in Figure 6 for the colored samples and the steel substrate. The unloading section of the curves for the colored samples was displaced to the right, indicating a lower hardness when compared with the substrate 9 . According to Page and Hainsworth ${ }^{22}$, this behavior is typical of soft films on hard substrates. As the interference film thickness is increased from $\sim 70 \mathrm{~nm}$ (brown) to $\sim 440 \mathrm{~nm}$ (green), the displacement of the unload curve to the right is more accentuated. This observation indicates that the influence of the substrate on mechanical properties of the composite is stronger for the thinner films

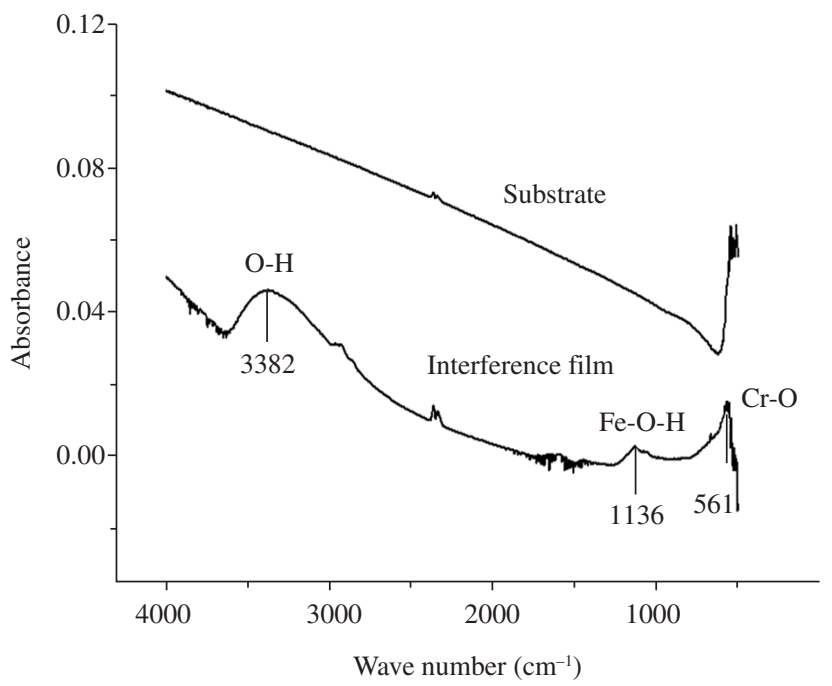

Figure 5. FTIR spectra of a gold colored interference film.

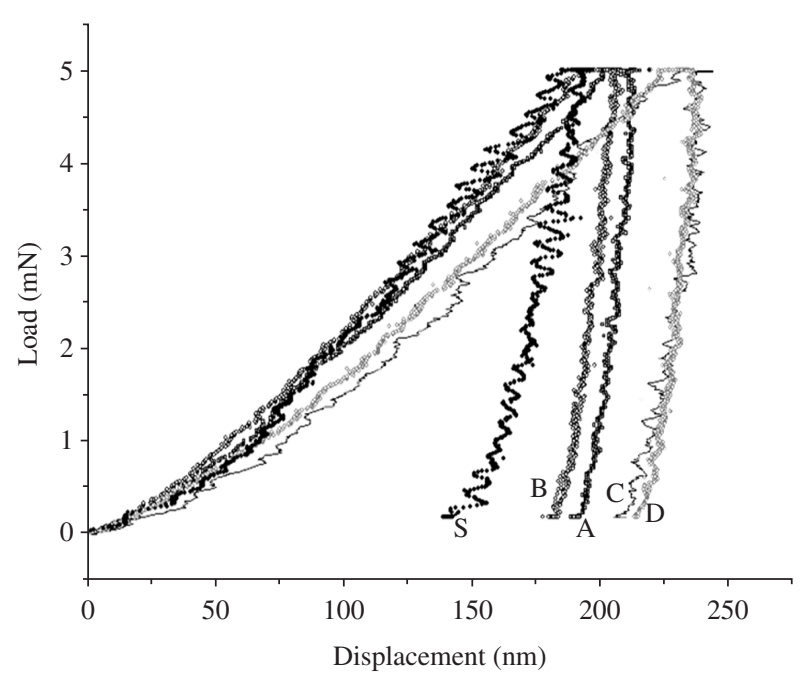

Figure 6. Load-displacement curves of the stainless steel substrate (S) and of specimens colored in brown (A), blue (B), gold (C) and green (D). 
with brown and blue interference colors than for the thicker films colored in gold and green. On the other hand, the proximity of the load-displacement curves for the thicker films (curves $C$ and D) in Figure 6 are due to the slight hardness difference between the green and gold films, reflecting a tendency towards the stabilization of the influence of film thickness on this property.

The values of indentation hardness $(\mathrm{H})$ and elastic modulus $(\mathrm{E})$ were calculated using the Oliver \& Pharr approach ${ }^{14}$ and plotted against film thickness in Figure 7. The data points represent the mean of five measurements, with standard deviations smaller than $10 \%$ of the mean values. The film thickness for the uncoated substrate was taken as zero, for simplicity. The total elastic-plastic deformation, $\mathrm{W}_{\text {tot }}$, calculated as the area underneath the load-displacement curves, is also plotted in Figure 7a, while the ratio H/E, called the plasticity index ${ }^{23}$, is plotted in Figure $7 \mathrm{~b}$. These results indicated that the film hardness decreased and $\mathrm{W}_{\text {tot }}$ increased as the coating thickness increased. There was also a tendency for the elastic modulus to decrease, causing an increase in the plasticity index as the film thickness increased. This behavior once again emphasizes that the substrate is harder than the interference films. The higher mechanical resistance of the substrate has been already observed in nanoscratching experiments performed

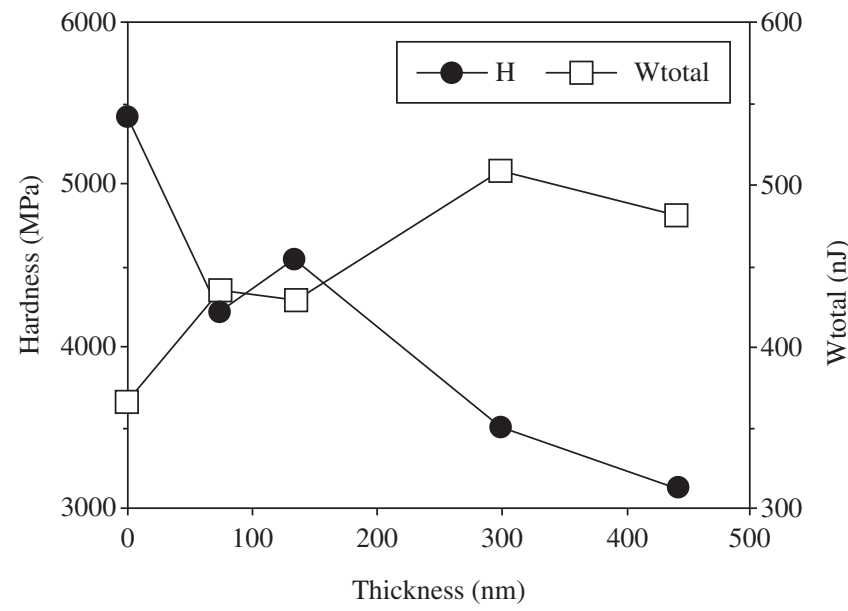

(a)

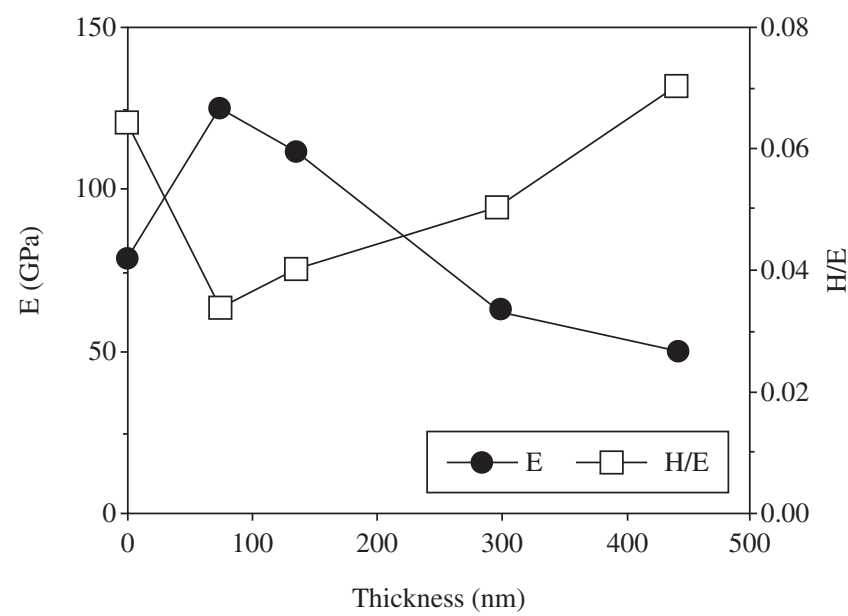

(b)

Figure 7. Parameters obtained in depth sensing indentation experiments as a function of film thickness: a) indentation hardness $\mathrm{H}$ and total elastic-plastic deformation $\mathrm{W}_{\text {total }}$, b) elastic modulus $\mathrm{E}$ and plasticity index $\mathrm{H} / \mathrm{E}$. on a gold colored stainless steel sample as compared to the uncoated substrate .

\subsection{Wear abrasion resistance}

The wear abrasion resistance of the interference films, expressed as the mean number of strokes in nine experiments (deviation less than $10 \%$ ), is plotted against film thickness in Figure 8. The H/E ratio calculated from the results of the depth-sensing experiments is also shown in this figure. It can be observed that the abrasion resistance increased as the thickness of the film increased and that the H/E ratio showed the same tendency. According to Leyland and Matttews ${ }^{23}$, a high plasticity index is often a reliable indicator of good wear resistance on a coating. They also comment that it is helpful for the film to have an elastic modulus which is slightly lower than the substrate. In this manner, the ranking of materials as regards their $\mathrm{H} / \mathrm{E}$ ratio can produce extremely close approximations to their ranking in terms of wear resistance. In the present work, the higher plasticity index found for the thicker gold and green films can explain their higher abrasion resistance in comparison with other colored samples with lower film thickness, such as those with brown and blue colors.

\section{Conclusions}

Characterization studies using several high resolution techniques, such as FESEM, AFM, and depth-sensing indentation were performed on interference films grown on an AISI 304 stainless steel. The main conclusions can be summarized as follows: the coloration of stainless steel by a pulse current method resulted in the growth of a porous thin film on the steel surface, which in turn increased its surface roughness. These interference films mainly consisted of hydrated chromium oxide containing iron. Increasing film thickness produced different colors and affected the mechanical properties of the coating-substrate system. Consequently, thicker films, such as those producing the gold and green colors, proved to be softer but more abrasion resistant.

\section{Acknowledgements}

The authors acknowledge the financial support from Fundação de Amparo à Pesquisa do Estado de Minas Gerais, and UC Berkeley for permission to use their Electron Microscopy Laboratory and the

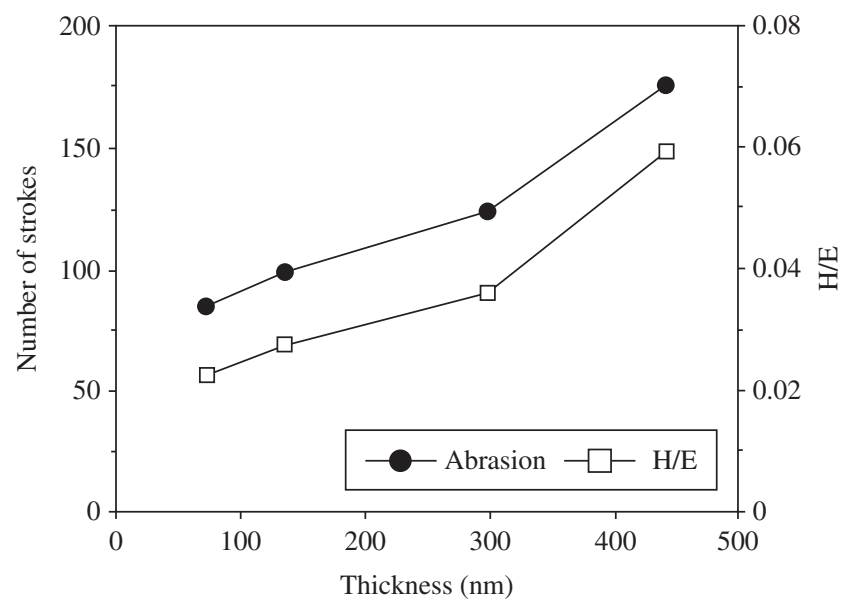

Figure 8. Number of strokes to expose the substrate as a function of film thickness and the plasticity index H/E. 
assistance provided by Gordon Vrdoljak in acquiring the FESEM images.

\section{References}

1. Evans TE. Film formation on stainless steel in a solution containing chromic and sulphuric acids. Corrosion Science 1977; 17:105-124.

2. Conrrado R, Bocchi N, Rocha-Filho RC, Biaggio SR. Corrosion resistance of colored films grown on stainless steel by the alternating potential pulse method. Electrochimica Acta 2003; 48: 2417-2424.

3. Evans TE, Hart AC, Skedgell AN. The nature of the film on colored stainless steel. Transactions of the Institute of Metal Finishing 1973; 51: 108-112.

4. Blower R, Evans TE. Introducing coloured stainless steel - A novel product and a new process. Sheet Metal Industries 1974; 51: 230-245.

5. Fujimoto S, Shibata T, Wada K, Tsutae T. The electrochemical conditions for coloured film formation on type 304 stainless steel with square wave polarization. Corrosion Science 1993; 35: 147-152.

6. Ogura K, Sakurai K, Uehara S. Room temperature coloration of stainless steel by alternating potential pulse method. Journal of Electrochemical Society 1994; 141: 648-651.

7. Ogura K, Lou W, Nakayama M. Coloration of stainless steel at room temperature by triangular current scan method. Electrochimica Acta 1996; 41(18): 2849-2853.

8. Lin CJ, Duh JG. Mechanical characteristics of colored film on stainless steel by the current pulse method. Thin Solid Films 1996; 287: 80-86.

9. Junqueira RMR, Andrade MS, Loureiro CRO, Buono VTL. Mechanical properties of interference thin films on colored stainless steel evaluated by depth-sensing nanoindentation. Surface and Coatings Technology 2006; 201: 2431-2437.

10. Ansell RO, Dickinson T, Povey AF. An X-ray photo-electron spectroscopic study of the films on coloured stainless steel and on coloured "Nilomag" Alloy 771. Corrosion Science 1978; 18: 245-256.

11. Sone Y, Tochihara M, Yoshioka K. Alternating current electrolysing method for colored stainless steel. In: Proceedings of International
Conference on Stainless Steels; 1991 Jun 10-13; Chiba, Japan. Tokyo: The Iron and Steel Institute of Japan; 1991. p. 1006-1011.

12. Fujimoto S, Tsujino K, Shibata T. Growth and properties of Cr-rich thick and porous oxide films on type 304 stainless steel formed by square wave potential polarisation. Electrochimica Acta 2001; 47: 543-551.

13. Kikuti E, Bocchi N, Pastol JL, Ferreira MG, Montemor MF, Cunha Belo $\mathrm{M}$, Simões AM. Composition and structure of coloured oxide films on stainless steel formed by triangular current scan and cathodic hardening treatment. Corrosion Science 2007; 49: 2303-2314.

14. Oliver WC, Pharr GM. An improved technique for determining hardness and elastic modulus using load and displacement sensing indentation experiments. Journal of Materials Research 1992; 7: 1564-1583.

15. Montgomery DC. Design and Analysis of Experiments. 3rd ed. New York: John Wiley; 1991.

16. Duncan DB. Multiple range and multiple F tests. Biometrics 1955; 11 : $1-42$.

17. Kerber SJ, Tverberg J. Stainless steel surface analysis. Advanced Materials and Processes 2000; 158: 33-36.

18. Parker M, Hartensein ML, Marcus RK. Effect of discharge parameters on emission yields in a radio-frequency glow discharge atomic-emission source. Spectrochimica Acta 1977; 52B: 567-578.

19. Lin CJ, Duh, JG. Elemental redistribution in colored film on SUS304 stainless steel produced by current pulse method. Surface and Coatings Technology 1996; 85: 175-182.

20. Lenglet M, Guillamet R, Lopitaux J, Hannoyer B. Characterisation des premières etapes de l'oxidation de l'acier inoxydable AISI 304 par spectrometrie I.R.F.T. Materials Research Bulletin 1990; 25: 575-583.

21. Musić S, Gotić M. Mössbauer. FTIR and FESEM investigation of iron oxides precipitated from FeSO4 solutions. Journal of Molecular Structrure 2007; 834-836: 445-453.

22. Page TF, Hainsworth SV. Using nanoindentation techniques for the characterization of coated systems: a critique. Surface and Coatings Technology 1993; 61: 201-208.

23. Leyland A, Matthews A. On the significance of the H/E ratio in wear control: a nanocomposite coating approach to optimised tribological behaviour. Wear 2000; 246: 1-11. 